\title{
Absorption of Sulfur Dioxide in Ionic Liquid Supported on Porous Silica Particles
}

\author{
Xiaoling Zha, Jin $\mathrm{Xu}$, Weifang $\mathrm{Yu}$ \\ College of Chemistry and Materials Engineering \\ Wenzhou University \\ Wenzhou, China \\ e-mail: ywf@wzu.edu.cn
}

\begin{abstract}
TMGL) has been studied for $\mathrm{SO}_{2}$ removal. However, before using industrial scale application, several problems need to be solved, for example, the influence on $\mathrm{SO}_{2}$ absorption at high temperature. This work investigates the $\mathrm{SO}_{2}$ sorption of the 1 , 1, 3, 3-tetramethylguanidinium lactate (TMGL) immobilized on porous silica particles under the conditions of low $\mathrm{SO}_{2}$ concentration. The effects of $\mathrm{SO}_{2}$ concentration and environment temperature were evaluated. The attained results clearly imply that both of them have significant influence on absorption performance. The $\mathrm{SO}_{2}$ absorption capacity reduced as the $\mathrm{SO}_{2}$ concentration decreased and the environment temperature increased.
\end{abstract}

Keywords-supported ionic liquids; desulfurizer; sulfur dioxide; absorption capacity

\section{INTRODUCTION}

Sulfur dioxide is one of the important air pollutants, leading to a serious problem and has drawn much attention throughout the world. [1-6] Ionic liquids were found to be key absorbents, due to negligible volatility, high thermal and chemical stability, and tunable chemical properties, which have been widely used in gas separation. For instance, Han et al. [7] first synthesized a base-functionalized IL, 1, 1, 3, 3tetramethylguanidinium lactate (TMGL), and reported that it can effectively absorb $\mathrm{SO}_{2}$ from a simulated flue gas with high absorption capacity ( $\left.0.978 \mathrm{~mol} \mathrm{SO}_{2} / \mathrm{mol} \mathrm{TMGL}\right)$ and high selectivity. From then, various ionic liquids were explored for $\mathrm{SO}_{2}$ capture.

Consider of the application of ionic liquids in industry, there are many problems need to be investigated.

(1)The high viscosity was the fatal weakness for $\mathrm{SO}_{2}$ removal by TMGL. To overcome this problem, Li et al. [8, 9] synthesized poly (1, 1, 3, 3-tetramethylguanidine acrylate) (PTMGA) and crosslinked porous copolymer particles. Unfortunately, their internal pore structures would be collapsed or mostly lost after many cycles of $\mathrm{SO}_{2}$ sorption. Subsequently, Li et al. [10] immobilized TMGL to porous silica $\left(\mathrm{SiO}_{2}\right)$ particles, which provided large gas-solid interface. They reported that it is an effective way to improve the absorption rate and capacity $\left(1.9 \mathrm{~mol} \mathrm{SO}_{2} / \mathrm{mol}\right.$ TMGL with pure $\mathrm{SO}_{2}$ ) of TMGL. However, the absorption capacity ( $0.48 \mathrm{~mol} \mathrm{SO} 2 / \mathrm{mol}$ TMGL) decreased dramatically when the flow gas was mixture gas containing $\mathrm{SO}_{2}$ of $2160 \mathrm{ppm}$.

(2)The real flue gas is not only a simple combination of
$\mathrm{N}_{2}$ and $\mathrm{SO}_{2}$. In addition, the concentration of $\mathrm{SO}_{2}$ emitting from flue gas is not very high, always around 2000ppm. Severa et al. [11] has reported the $\mathrm{SO}_{2}$ sorption by loading ionic liquid on activated carbon sorbents under simulated atmospheric conditions, and proved the importance of testing the performance of the ionic liquid absorption of $\mathrm{SO}_{2}$ under simulated real world conditions.

(3)The temperature of flue gas is very high when it just emitted. A systematic research about the influence on the $\mathrm{SO}_{2}$ absorption by TMGL at high temperature is not reported.

In this study, the $\mathrm{SO}_{2}$ absorption performance by TMGL loaded porous silica $\left(\mathrm{TMGL} / \mathrm{SiO}_{2}\right)$ at relatively low $\mathrm{SO}_{2}$ concentration range (below 5000ppm) and temperature was be investigated.

\section{EXPERIMENTAL SECTION}

\section{A. Materials}

1,1,3,3-tetramethylguanidinium (TMG, $\geq 99.0 \%$, Aladdin Co., LTD., China), L-lactic acid (86\%, Sigma-aldrich (Wuxi) Life Science \& Technology Co., LTD., China) and silica particles $\left(\mathrm{SiO}_{2}\right.$, particle diameter range is 150 280 $\mu \mathrm{m}$, Sigma-aldrich Co., USA), nitrogen $\left(\mathrm{N}_{2}, \geq 99.0 \%\right.$, Wenzhou Changsheng gas Co., LTD., China), and $\mathrm{N}_{2} / \mathrm{SO}_{2}$ mixture gas with $2.60 \% \mathrm{SO}_{2}$ (Changzhou Jinghua industrial gas Co., LTD., China)

\section{B. Preparation and Characterization of $\mathrm{TMGL} / \mathrm{SiO}_{2}$}

$\mathrm{TMGL} / \mathrm{SiO}_{2}$ with different immobilization ratio was prepared through the impregnation-vaporization process ${ }^{[10]}$, and the $\mathrm{TMGL} / \mathrm{SiO}_{2}$ ratio $\mathrm{x} / 1$ was expressed as $\mathrm{TMGL} / \mathrm{SiO}_{2}-$ $\mathrm{x} / 1$, equal to the $\mathrm{TMGL} / \mathrm{SiO}_{2}$ feed ratio $\mathrm{x} / 1$.

TMGL/SiO $2-\mathrm{X} / 1$ and TMGL were characterized by Thermal Gravimetric Analyzer (TGA). The samples were heated to $600{ }^{\circ} \mathrm{C}$ in $10{ }^{\circ} \mathrm{C} / \mathrm{min}$ under nitrogen. A Micromeritics ASAP 2020 instrument was used to obtained properties of particles, including the pore size distribution, pore volume, and surface area. 


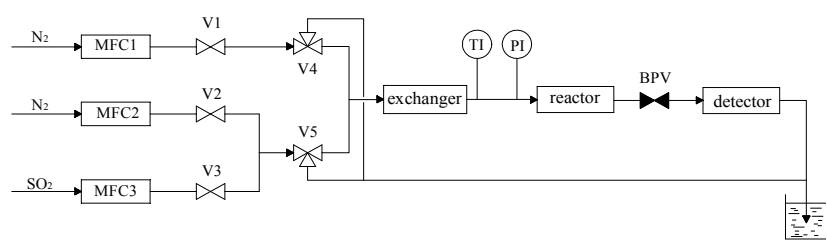

Figure 1. Experimental Setup.

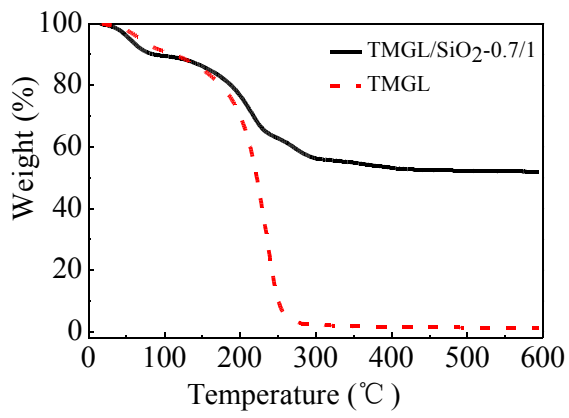

Figure 2. TGA curves of the TMGL/ $/ \mathrm{SiO}_{2}-0.7 / 1$ and TMGL.

\section{Absorption Experiment}

The prepared particles with different loadings $\left(\mathrm{TMGL} / \mathrm{SiO}_{2}-\mathrm{x} / 1\right)$ were used in the sorption experiments. The simulated flue gas with different $\mathrm{SO}_{2}$ concentration and total flow rate were controlled by changing $\mathrm{N}_{2}$ and $\mathrm{SO}_{2}$ mass flowmaters. The mixture gas flowed through the Modular Microreaction System (OI-MMRS 01.2009, Ehrfeld Mikrotechnik BTS GmbH, Germany), involving coax heat exchanger, pressure sensor module, and temperature sensor module and cartridge reactor. After sorption, the mixture gas flowed through the Bruker Alpha FT-IR Spectrometer (Bruker Optik Asia Pacific Limited, Germany) for the determination of $\mathrm{SO}_{2}$ concentration. The experimental setup is shown in Figure 1.

Due to scarcely absorb $\mathrm{N}_{2}$ on TMGL [12], in this work $\mathrm{N}_{2}$ was used as carrier gas and the effect of $\mathrm{N}_{2}$ on absorption performance was neglected. Step 1, valve 1 and 4 opened for the $\mathrm{N}_{2}$ gas passed the experiment setup. Then, the sorbents with the same volume were filled in the reactor, while controlling the temperature by using circulating water bath connected to the heat exchanger. Step 2, valve 2, 3 and 5 were opened (with valve 1 and 4 closed), the mixture gas with a certain $\mathrm{SO}_{2}$ concentration flowed into the system, while the change in the $\mathrm{SO}_{2}$ concentration was measured and recorded by the flue gas analyzer.

\section{Results And Discussion}

\section{A. Characterization}

The prepared particles with different TMGL loadings and TMGL were investigated by TGA to get their weight ratio,

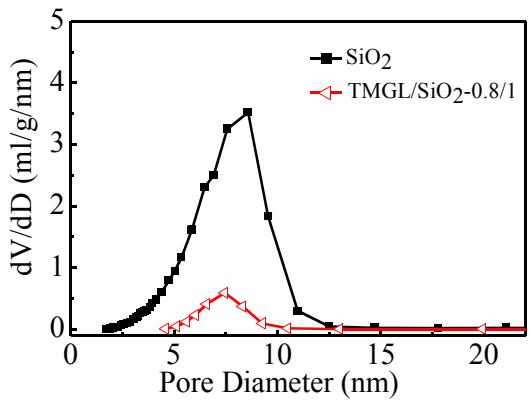

Figure 3. Pore size distribution of $\mathrm{SiO}_{2}, \mathrm{TMGL} / \mathrm{SiO}_{2}-0.8 / 1$.

shown in Figure 2.Compared with the TGA curve of the TMGL, the weight loss was about $36 \%$ between $130{ }^{\circ} \mathrm{C}$ and $350{ }^{\circ} \mathrm{C}$ as the TGA curve of the TMGL/ $\mathrm{SiO}_{2}-0.7 / 1$ sample shown, which can be considered as the decomposion of TMGL. Obviously, the change of the weight was correlated with the $\mathrm{TMGL} / \mathrm{SiO}_{2}$ feed ratio.

Figure 3 showed the particle size distribution of pours silica and $\mathrm{TMGL} / \mathrm{SiO}_{2}-0.8 / 1$. Obviously, the pore diameter of sorbents decreased after TMGL was immobilized on $\mathrm{SiO}_{2}$.

\section{B. Effect of $\mathrm{SO}_{2}$ Concentration on Absorption Performance of $\mathrm{TMGL} / \mathrm{SiO}_{2}$}

Different $\mathrm{SO}_{2}$ concentrations $(0.1 \%, 0.2 \%, 0.3 \%, 0.4 \%$, $0.5 \%$ ) and total flow rate of $200 \mathrm{ml} / \mathrm{min}$ was controlled by $\mathrm{N}_{2}$ mass flowmeter and $\mathrm{SO}_{2}$ mass flowmeter. The temperature of the water bath was set to $45^{\circ} \mathrm{C}, \mathrm{TMGL} / \mathrm{SiO}_{2-}$ $0.2 / 1$ and $\mathrm{TMGL} / \mathrm{SiO}_{2}-0.4 / 1$ were used as sorbents, the effect of $\mathrm{SO}_{2}$ concentration as shown in Figure 4.

As seen in the breakthrough curves, with the increase of $\mathrm{SO}_{2}$ concentrations, the absorption rate showed an upward trend. It is more obvious for $\mathrm{TMGL} / \mathrm{SiO}_{2}-0.4 / 1$, with the $\mathrm{SO}_{2}$ concentration increased from $0.1 \%$ to $0.5 \%$, the breakthrough time reduced from $50 \mathrm{~min}$ to $15 \mathrm{~min}$.

The degree of difficulty to reach phase equilibrium $\left(\mathrm{t}_{0.9}\right)$ was proposed by Chen et al. [13] to evaluate the absorption kinetics. In this work, $\mathrm{t}_{0.9}$ and the $\mathrm{SO}_{2}$ absorption capacity were calculated, shown in Table I. It is obvious that the $\mathrm{SO}_{2}$ absorption capacity of $\mathrm{TMGL} / \mathrm{SiO}_{2}-0.2 / 1$ and $\mathrm{TMGL} / \mathrm{SiO}_{2-}$ $0.4 / 1$ increased as the $\mathrm{SO}_{2}$ concentration increased. In contrast, the value of $\mathrm{t}_{0.9}$ gradually reduced with the increase of $\mathrm{SO}_{2}$ concentration, which was more obvious for the higher $\mathrm{TMGL} / \mathrm{SiO}_{2}$ ratio. Under the same $\mathrm{SO}_{2}$ concentration, the absorption capacity of TMGL/ $/ \mathrm{SiO}_{2}-0.4 / 1$ was always bigger than that of $\mathrm{TMGL} / \mathrm{SiO}_{2}-0.2 / 1$. 


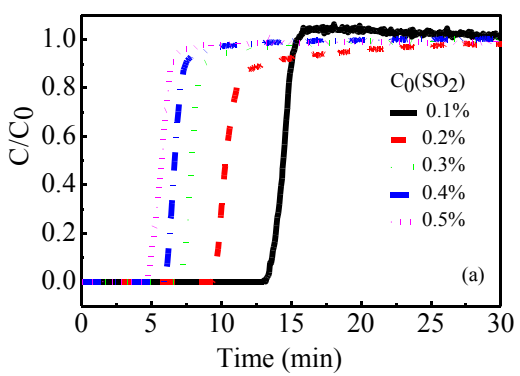

The Results of SO2 Sorption Under the Different SO2 Concentration

$\mathrm{SO}_{2}$ Absorption Capacity (AC) and the degree of difficulty to reach phase equilibrium ( $\left.\mathrm{t}_{0.9}\right)$

\begin{tabular}{|c|c|c|}
\hline \multirow{2}{*}{$\begin{array}{c}\text { Concentration } \\
\text { (\%) }\end{array}$} & \multicolumn{2}{|c|}{$\mathrm{TMGL} / \mathrm{SiO}_{2}-0.2 / 1$} \\
\hline & $A C\left(\mathrm{~mol} \mathrm{SO} \mathrm{O}_{2} / \mathrm{mol} \mathrm{TMGL}\right)$ & $t_{0.9}(\min )$ \\
\hline 0.1 & 0.1170 & 12.6 \\
\hline 0.2 & 0.2173 & 11.0 \\
\hline 0.3 & 0.2292 & 7.8 \\
\hline 0.4 & 0.2542 & 6.2 \\
\hline 0.5 & 0.2749 & 5.7 \\
\hline
\end{tabular}

\section{Effect of Temperature on Absorption Performance of $\mathrm{TMGL} / \mathrm{SiO}_{2}$}

The effect of environment temperature on $\mathrm{SO}_{2}$ sorption was studied by setting up the circulating water bath temperature whilst maintaining the $\mathrm{SO}_{2}$ concentration $(0.4 \%)$ and the total flow rate $(500 \mathrm{ml} / \mathrm{min})$ constant, shown in Figure 5. For the different sorbent (TMGL/ $\mathrm{SiO}_{2}-0.6 / 1$, $\mathrm{TMGL} / \mathrm{SiO}_{2}-0.8 / 1$ ), the rate of $\mathrm{SO}_{2}$ sorption increased as the temperature increased. The absorption performance indicates that chemical absorption involved in the process of $\mathrm{SO}_{2}$ sorption.

However, as seen in Table II, with the environment temperature increased from $30{ }^{\circ} \mathrm{C}$ to $80{ }^{\circ} \mathrm{C}$, the $\mathrm{SO}_{2}$ absorption capacity dropped by $30 \%$ at least. In addition, controlled the experimental conditions unchanged, the different between TMGL/ $\mathrm{SiO}_{2}-0.6 / 1$ and $\mathrm{TMGL} / \mathrm{SiO}_{2}-0.8 / 1$ are not obvious on the valve of absorption capacity. The absorption performance can be explained by the different pore characteristics with the $\mathrm{TMGL} / \mathrm{SiO}_{2}$ ratio changed.

\section{CONCLUSION}

In this work, the $\mathrm{SO}_{2}$ sorption performance on $\mathrm{TMGL} / \mathrm{SiO}_{2}$ under different conditions was investigated, including the $\mathrm{SO}_{2}$ concentration and the environment temperature. Compared to the results reported in the literature for the capacity of $\mathrm{TMGL} / \mathrm{SiO}_{2}$ reached $1.9 \mathrm{~mol}$ $\mathrm{SO}_{2}$ per mol TMGL with pure $\mathrm{SO}_{2}$ gas, the absorption capacity significantly is smaller under the condition of the low $\mathrm{SO}_{2}$ concentration. Results under different temperature suggest that the significant effect of temperature on the $\mathrm{SO}_{2}$ absorption performance. Therefore, the $\mathrm{SO}_{2}$ absorption by

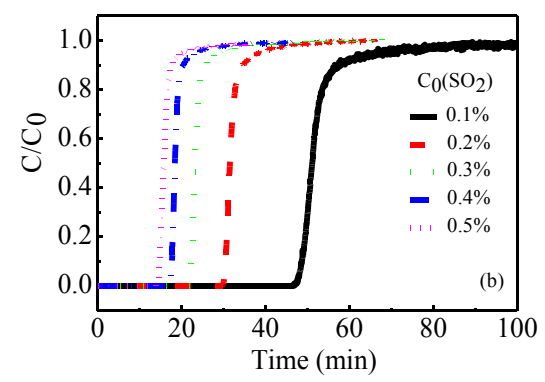

Figure 4. Effect of $\mathrm{SO}_{2}$ concentration on absorption performance of $\mathrm{TMGL} / \mathrm{SiO}_{2}-0.2 / 1$ (a), TMGL/SiO $2-0.4 / 1$ (b).
$\mathrm{TMGL} / \mathrm{SiO}_{2}$ under the high temperature should be avoided. It should be pointed out that further work need be carried. For example, the real flue gas is not only involve $\mathrm{SO}_{2}$ with low concentration, but also other gases included, such as $\mathrm{NO}_{x}, \mathrm{CO}$, which may have influence on the $\mathrm{SO}_{2}$ absorption behavior.
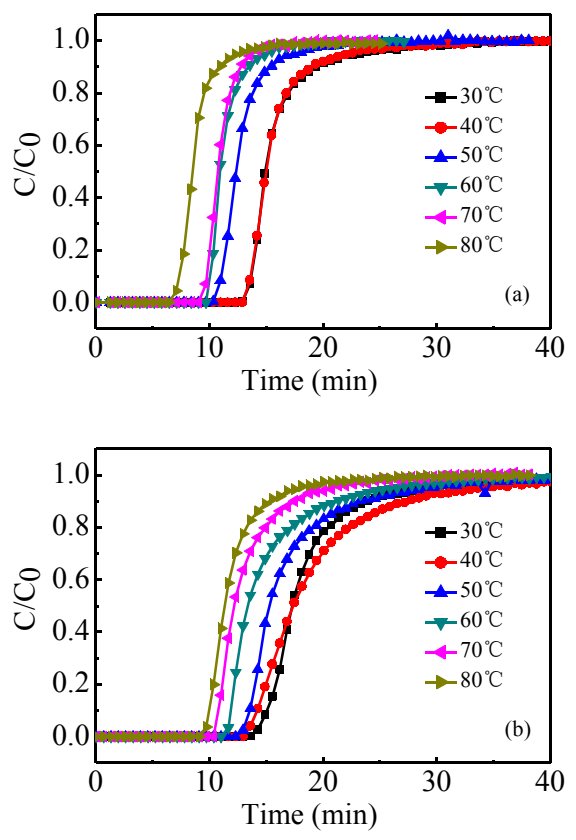

Figure 5. Effect of temperature on absorption performance of TMGL/SiO ${ }_{2}-$ $0.6 / 1$ (a), TMGL/SiO $2-0.8 / 1$ (b). 
TABLE II. The Results of SO2 Sorption in DifFerent Temperature

\begin{tabular}{|c|c|c|c|c|}
\hline \multirow{3}{*}{$\begin{array}{c}\text { Temperature } \\
\left({ }^{\circ} \mathrm{C}\right)\end{array}$} & \multicolumn{4}{|c|}{$\mathrm{SO}_{2}$ Absorption Capacity $(\mathrm{AC})$ and the degree of difficulty to reach phase equilibrium $\left(\mathrm{t}_{0.9}\right)$} \\
\hline & \multicolumn{2}{|c|}{$\mathrm{TMGL} \mathrm{SiO}_{2}-0.6 / 1$} & \multicolumn{2}{|c|}{$T M G L / S i O_{2}-0.8 / 1$} \\
\hline & 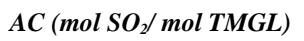 & $t_{0.9}(\min )$ & $\mathrm{AC}\left(\mathrm{mol} \mathrm{SO} \mathrm{O}_{2} / \mathrm{mol} \mathrm{TMGL}\right)$ & $t_{0.9}(\min )$ \\
\hline 30 & 0.4777 & 14.7 & 0.4229 & 18.2 \\
\hline 40 & 0.4445 & 14.7 & 0.4848 & 21.4 \\
\hline 50 & 0.3833 & 11.9 & 0.3809 & 18.5 \\
\hline 60 & 0.3605 & 10.4 & 0.3541 & 16 \\
\hline 70 & 0.3004 & 10.0 & 0.3129 & 13 \\
\hline 80 & 0.2724 & 8.4 & 0.2803 & 11.5 \\
\hline
\end{tabular}

\section{ACKNOWLEDGMENT}

The authors would like to thank the Natural Science Foundation of Zhejiang Province (Y5110174) for financial supports as well as Wenzhou University for assistance with sorption measurements.

\section{REFERENCES}

[1] J. Wieckowska, "Catalytic and adsorptive desulphurization of gases," Catal. Today, vol. 24, pp. 405-465, July 1995.

[2] S. Kiil, M. L. Michelsen, and K. Dam-Johansen, "Experimental Investigation and Modeling of a Wet Flue Gas Desulfurization Pilot Plant,” Ind. Eng. Chem. Res., vol. 37, pp. 2792-2806, May 1998.

[3] B. B. Hansen, S. Kiil, J. E. Johnsson, and K. B. Sønder, "Foaming in Wet Flue Gas Desulfurization Plants: The Influence of Particles, Electrolytes, and Buffers," Ind. Eng. Chem. Res., vol. 47, pp. 32393246, April 2008.

[4] X. Ma, T. Kaneko, T. Tashimo, T. Yoshida, and K. Kato, "Use of limestone for $\mathrm{SO}_{2}$ removal from flue gas in the semidry FGD process with a powder-particle spouted bed," Chem. Eng. Sci., vol. 55, pp. 4643-4652, October 2000

[5] M. Tokumura, M. Baba, H. T. Znad, Y. Kawase, C. Yongsiri, and K. Takeda, "Neutralization of the Acidified Seawater Effluent from the Flue Gas Desulfurization Process: Experimental Investigation, Dynamic Modeling, and Simulation," Ind. Eng. Chem. Res., vol. 45, pp. 6339-6348, July 2006 ..
[6] G. Astarita, D. W. Savage, and A. Bisio, Gas Treating with Chemical Solvents. New York: J. Wiley and Sons, 1983.

[7] W. Z. Wu, B. X. Han, H. X. Gao, Z. M. Liu, T. Jiang, and J. Huang, "Desulfurization of Flue Gas: $\mathrm{SO}_{2}$ Absorption by an Ionic Liquid," Angew. Chem. Int. Ed. vol. 43, pp. 2415-2417, April 2004.:

[8] D. An, L.B. Wu, B.G. Li, and S.P. Zhu, "Synthesis and $\mathrm{SO}_{2}$ Absorption/Desorption Properties of Poly $(1,1,3,3-$ tetramethylguanidinium acrylate)," Macromolecules, vol. 40, pp. 3388-3393, April 2007.

[9] L. B. Wu, D. An, J. Dong, Z. M. Zhang, B. G. Li, and S. P. Zhu, "Preparation and $\mathrm{SO}_{2}$ Absorption/Desorption Properties of Crosslinked Poly(1,1,3,3-Tetramethylguanidinium Acrylate) Porous Particles," Macromol. Rapid Commun. vol. 27, pp. 1949-1954, November 2006.

[10] Z. M. Zhang, L. B. Wu, J. Dong, B. G. Li, and S. P. Zhu, "Preparation and $\mathrm{SO}_{2}$ Sorption/Desorption Behavior of an Ionic Liquid Supported on Porous Silica Particles," Ind. Eng. Chem. Res., vol. 48, pp.2142-2148, January 2009.

[11] J. L. Anthony, E. J. Maginn, and J. F. Brennecke, "Solubilities and Thermodynamic Properties of Gases in the Ionic Liquid 1-n-Butyl-3methylimidazolium Hexafluorophosphate," J. Phys. Chem. B, vol. 106, pp. 7315-7320, May 2002.

[12] J. L. Anthony, E. J. Maginn, and J. F. Brennecke, "Solubilities and Thermodynamic Properties of Gases in the Ionic Liquid 1-n-Butyl-3methylimidazolium Hexafluorophosphate," J. Phys. Chem. B, vol. 106, pp. 7315-7320, May 2002.

[13] Y. Chen, J. Han, T. Wang, and T. Mu, "Determination of Absorption Rate and Capacity of $\mathrm{CO}_{2}$ in Ionic Liquids at Atmospheric Pressure by Thermogravimetric Analysis," Energy Fuels. vol. 25, pp. 5810-5815, November 2011 